\title{
Revisitando a noção de gênero musical em tempos de cultura musical digital ${ }^{1}$
}

\author{
Jeder Janotti Jr.! \\ https://orcid.org/0000-0003-3975-7433
}

Simone Pereira de Sál

https://orcid.org/0000-0002-0557-6514

I - UFPE

Recife (PE), Brasil

II - UFF

Niterói (RJ), Brasil

Resumo: O artigo tem por objetivo revisitar a noção de gênero musical, buscando mapear seu percurso nos estudos de comunicação no Brasil nas duas últimas décadas, identificando alguns dos principais debates em torno da questão e apontando as reconfigurações que garantiram sua produtividade em tempos de cultura digital.

Palavras-chave: gênero musical; categorização musical; estudos brasileiros de comunicação.

Abstract: Revisiting the notion of musical genre in times of digital music culture - The paper aims to revisit the notion of musical genre, seeking to map its course in communication studies in Brazil in the last two decades, identifying some of the main debates around the issue and pointing out the reconfigurations that guaranteed its productivity in times of digital culture.

Keywords: musical genre; musical categorization; Brazilian communication studies.

\section{Introdução}

A noção de gênero musical tem sido uma baliza para as discussões do campo da pesquisa em música e comunicação no Brasil há pelo menos duas décadas. Partindo de diálogos com autores tais como Frith (1996), Negus; Pickering (2004) e Fabbri (2004), desenvolveu-se uma

1 Versão modificada do paper apresentado no XXVII Encontro Anual da Compós, PUC-MG - Belo Horizonte, 2018. O trabalho apresenta resultados de pesquisas apoiadas pelo edital PROCAD/CAPES e pelo CNPq (PQ). 
discussão no campo dos estudos comunicacionais brasileiros, que apontava para a importância da noção de gênero como mediador das relações entre produtores e consumidores de música, para além de sua articulação como rótulo mercadológico utilizado "para organizar as prateleiras das lojas de venda de discos" (FRITH; 1996); e também para além da visão do gênero musical como o resultado de um conjunto estável de sonoridades.

Contudo, o advento da cultura digital, a expansão da Internet ao longo das duas últimas décadas e a consolidação das redes sociais como ambientes midiáticos produziram um cenário de transformações na cadeia produtiva da música, tais como a crise das vendas de formatos físicos e a reconfiguração dos modelos de vendas das grandes gravadoras. (HERSCHMANN, 2010). Cenário no qual as prateleiras das lojas de discos já não são os centros primordiais de consumo musical e as plataformas de música por streaming reconfiguram as categorizações através dos sistemas de recomendação aos usuários, baseados nas preferências dos ouvintes e práticas de folksonomia (PEREIRA DE SÁ; 2009, AMARAL; 2007; AMARAL e AQUINO; 2008; DE MARCHI 2017)2

Outros aspectos da cultura digital tais como as possibilidades de empreendedorismo artístico independente das grandes gravadoras (PEREIRA DE SÁ; BITTENCOURT \& DOMINGUES; 2016), o fortalecimento das práticas da cultura remix e ativismo dos fandoms nas redes sociais (AMARAL e MONTEIRO; 2012; MONTEIRO; 2011; CONTER, 2016) e o crescente hibridismo entre gêneros outrora circunscritos à circulação em seus territórios são exemplos da reconfiguração do cenário da cultura musical, abalando certezas e desafiando os pesquisadores em busca de novas ferramentas teórico-metodológicas.

Paralelamente, um segundo debate, advindo do diálogo com a perspectiva de autores do "Sul Global" (COMAROFF, J.; COMAROFF, J.L.; 2016), também nos leva a problematizar a categoria de gênero musical, criticada por ser utilizada de maneira etnocêntrica para reificar dicotomias entre centro e periferia e também para definir e normalizar as regas de um gênero musical a partir da perspectiva norte-americana ou anglo-saxônica (NILSSON; 2016; SANTOS; 2018).

Frente a esse cenário, nosso objetivo é o de revisitar a noção de gênero musical, partindo da premissa de que ele permanece como um marcador importante do debate, mas que carece de ser rediscutido à luz desse conjunto de reconfigurações. Ou seja: ao mesmo tempo que reiteramos a sua importância, propomos um percurso através de trabalhos recentes que tratam do tema³, a fim de ampliar a sua ressonância, incorporando as questões de rotulação e valor advindas do modo como as músicas são produzidas, disponibilizadas, consumidas e apropriadas na atualidade.

2 O player Spotify, por exemplo, possui uma aba "Em Turnê" que aponta os próximos shows dos músicos que estão sendo ouvidos e os shows próximos à localização do usuário na aba "Recomendados Para Você", além de outros recursos tais como teias de indicações de artistas similares aos que estamos ouvindo, sugestão de rádios baseadas em nossos cardápios musicais.

3 Cujo recorte se deu a partir de filtragem de trabalhos publicados em revistas de comunicação, somados a trabalhos apresentados nos GTs de Cibercultura e de Som e Música da Compós, de Música e Entretenimento da Intercom e teses e dissertações dos últimos dez anos (2007-2017). A menção a tais obras não é exaustiva. 


\section{Revisitando a noção de gênero musical}

Em trabalhos anteriores, discutimos a importância da noção de gênero musical como um dos mediadores centrais do processo de fruição da música, uma vez que, conforme sublinha Frith (1996), são as expectativas e convenções de gênero que orientam nossas escolhas no cenário musical. Negus e Pickering (2004), por sua vez, argumentam que os gêneros são fundamentais para mediarem as relações entre produtores e consumidores, ressaltando que eles nos ajudam a responder a três perguntas centrais da circulação musical: 1) "onde essa música se encaixa?"; 2) "com o que se parece?"; 3) "quem vai comprar?".

Enfatizando o caráter sócio-cultural das classificações por gênero, Fabbri (1981) sugere cinco eixos para sua análise: a) "convenções de composição e de instrumentação"; b) "regras semióticas" - que dizem respeito não somente às letras, mas a como a música, de maneira mais ampla, utiliza-se de símbolos e sentimentos para se comunicar; c) as "regras comportamentais", tais como rituais de performance musical (ao vivo ou gravadas); d) "regras sociais e ideológicas" - que apontam para os valores que enformam os consumidores do gênero musical; e) "convenções econômicas e jurídicas" em torno da cadeia produtiva fonográfica e da propriedade intelectual.

Dialogando com essas perspectivas, Janotti Jr (2003) sintetiza e aglutina os cinco eixos de Fabbri em três novas articulações: 1) regras econômicas que envolvem práticas de consumo e endereçamentos dos produtos musicais; 2) regras semióticas que abarcam os processos de produção de sentidos, intertextualidades e paratextualidades; 3 ) regras técnicas e formais tais como as técnicas de execução e habilidades específicas, a valorização de certos instrumentos musicais, o ritmo, a harmonia, a melodia e as relações entre palavras e sonoridades.

A discussão é importante para nossa reflexão, dentre outros motivos, por apontar para os aspectos extra-musicais presentes na categorização por gênero musical e, ao mesmo tempo, pelo caráter tensivo desta noção. Ou seja, longe de serem definitivas ou imanentes ao universo musical, a discussão demonstra que a noção de gênero musical supõe conflitos, negociações e rearranjos sucessivos. Assim, seguimos Fabbri, que vem reiterando que os gêneros musicais não são uma camisa de força em relação às obras pontuais. Para ele, os processos de rotulação da produção musical são processos dinâmicos, diálogos contínuos entre os aspectos de produção, circulação, consumo e apropriação da música.

Algumas pessoas veem a vida musical como uma história de indivíduos, ou seja, trabalhos individuais, que outras pessoas (substancialmente por razões não musicais) classificam em tipos. Depois de um quarto de século, eu me convenci do contrário: a vida musical é um contínuo processo de categorização, produção e reconhecimento de ocorrência de tipos, desde os níveis semióticos mais básicos (múltiplas ocorrências de um trabalho, seja uma canção, uma sinfonia, uma suíte para violoncelo, a fita gravada de um álbum etc.) ao mais articulado nível (ocorrências do idioleto de um autor, de um estilo ou gênero musical) (FABBRI, 2012, p. 19, tradução nossa). 
Persistindo no diálogo com Fabbri, diferentes autores acabaram ora por privilegiar uma perspectiva culturalista, ora uma abordagem semiótica dos gêneros musicais. Negus e Pickering (2004), por exemplo, centraram seu estudo no desenvolvimento da ideia de "cultura de gênero", reforçando o papel das comunidades que abarcam músicos, produtores, críticos e fãs como alicerces dos gêneros musicais. A partir do reconhecimento da "cultura de gênero" como uma categoria que permite a articulação entre centros e localidades na vivência das categorizações musicais, Holt (2003) trabalhou as noções de gênero e estilo musical como lugares de processos dinâmicos entre gênero, subcategorias e assinaturas singulares no universo da música, conforme se pode perceber no exemplo aqui citado,

Heavy metal, por exemplo, é uma forma de rock, mas também é considerado um gênero com suas próprias subcategorias e então, nós temos, pelo menos, três níveis de gênero, mas nós não podemos simplesmente adicioná-los como em uma taxonomia de uma família biológica porque eles não estão organizados deste modo na mente das pessoas. O conceito de estilo é frequentemente aplicado às subcategorias dos gêneros e eu pego essa dimensão hierárquica como um princípio em minha distinção ampla entre estilo e gênero (HOLT, 2003, p. 83, tradução nossa).

Já Lopez Cano propôs uma delimitação das relações entre gênero e estilo a partir de um diálogo com a semiótica, buscando precisar melhor estas noções. Nesta perspectiva, para este autor, o que denominamos estilo é uma competência em meio à "cultura de gênero":

De acordo com recentes teorias musicais de extração semiótica e cognitiva, quando fazemos, interpretamos, dançamos ou compreendemos músicas, estamos lançando uma série de procedimentos e operações cognitivas que variam segundo o tipo de música com a qual estamos interatuando (LÓPEZ CANO, 2004, p.340, tradução nossa).

Assim, antes de serem categorizações musicais homogeneizantes, os gêneros musicais permitem que músicos e audiências estabeleçam balizas para as disputas de gosto, ao mesmo tempo que permitem a construção de assinaturas específicas que se tornam as marcas distintivas do artista. Este processo ocorre a partir de ampla rede de articulações que envolve sonoridades, produtos audiovisuais, processos de recomendação, agrupamento de produções, afirmações de gosto, letras, biografias, críticas culturais, entrevistas etc.

Este aspecto da discussão é um dos destaques da atual produção brasileira sobre os gêneros musicais, pois é a partir do jogo entre as marcas distintivas dos artistas e o reconhecimento do pertencimento aos gêneros musicais que vários dos trabalhos produzidos no país vêm demonstrando a importância de se pensar a música popular massiva através das categorizações musicais, dos estilos e das assinaturas dos músicos. Assim, mencionamos, entre outras, as discussões em torno das disputas de rotulação entre 
rap e samba em Marcelo D2 (JANOTTI JR., 2003), dos diferentes acionamentos do forró em sua versão tradicional e no forró eletrônico (TROTTA, 2014), da presença da vertente pop no funk (PEREIRA DE SÁ, 2017), dos trânsitos da banda Pública entre as categorizações indie rock e rock gaúcho (ESTIVALET, 2017), das tensões sobre o rótulo rap no trabalho solo de Mano Brown (VIEIRA DA SILVA, 2017).

Antes de serem somente estudos de caso, estas pesquisas fornecem bases para a reconfiguração continuada das definições de gênero musical. E através delas, torna-se possível compreender a importância do jogo processual que marca as constantes disputas entre o não reconhecimento de pertencimento a um gênero musical específico - quando músicos buscam "assinaturas singulares" - e o contínuo processo de categorização exercido nas performances de gosto por parte de críticos, fãs, apreciadores e usuários no universo da música.

\section{Gêneros musicais, poder e territorialidades}

Na busca por operacionalizar a noção em debate, parte dos estudos no Brasil se voltou para a articulação entre gêneros musicais e suas territorialidades, entendendo que som e música mediam amplas relações sócio-espaciais - seja para atrelar determinada prática musical a um sentimento de identidade local ou regional; seja para delimitar espaços simbólicos de circulação de gêneros; seja para nos remeter a ambientes virtuais de circulação de canções e audiovisuais em redes sociais e plataformas musicais ou para demarcar e enquadrar os gêneros dentro de uma ordem hierárquica que articula cenários globais e locais.

Conforme já apontamos (PEREIRA DE SÁ et al; 2013), som e música estabelecem com o espaço urbano uma via de mão dupla: por um lado, bairros e/ou cidades inspiram compositores, diretores e criadores do campo musical; por outro lado, letras de músicas ou mesmo um gênero musical podem ressignificar o imaginário sobre uma cidade ou país, (re)construindo os mapas citadinos.

Assim, num primeiro momento, a noção de "cenas musicais" - explorada sobretudo no diálogo com o trabalho de Straw - é uma produtiva porta de entrada para a abordagem das dinâmicas de sociabilidade, afeto e gregarismo que envolvem a música nos espaços urbanos. Como já havia apontado a autora (PEREIRA DE SÁ; 2011), antes de tratar-se de uma clivagem entre gêneros e cenas musicais, a abordagem das cenas abre outras perspectivas para se abordar os gêneros musicais em suas articulações espaciais.

Explorando esta dimensão espacial, entendemos que a noção de cena musical se torna útil para o pesquisador cartografar as sociabilidades que emergem em diferentes regiões de uma cidade, ao mesmo tempo que apontam para a organização das comunidades de gosto através dos espaços metropolitanos. Outro aspecto a ser ressaltado é que a noção de cena musical também permite a apreensão da dimensão política da ocupação 
dos espaços por grupos e coletivos, criando circuitos concretos marcados pelos rastros dos agrupamentos em movimento, enfatizando a efervescência das cidades enquanto espaços sociais vívidos e produtivos. Finalmente, também cabe destacar o fato de que as cenas não só se apropriam de espaços da cidade mas são por eles moldadas (FERNANDES; HERSCHMANN; TROTTA, 2015).

Tomemos dois exemplos de gêneros vinculados à sua origem carioca, mas que gozam de valor simbólico diametralmente opostos. O primeiro é o funk carioca. Oriundo das favelas e espaços periféricos da cidade do Rio de Janeiro nos anos 1980, o gênero se modificou, ganhou visibilidade nacional, ganhou verniz pop, se internacionalizou; mas ainda carrega o estigma que o vincula aos territórios de origem, sendo criticado como música "de baixa qualidade" por parte da crítica musical e dos consumidores de música no Brasil (PEREIRA DE SÁ, CUNHA; 2014). Por outro lado, a bossa nova, gênero também oriundo da cidade do Rio de Janeiro - contudo de um espaço "nobre" da cidade, que é o ambiente dos apartamentos e bares da zona sul boêmia, chique e praiana dos anos de 1960/70, eternizado na letra de "Garota de Ipanema" - permanece como "a" referência de bom gosto e sofisticação musical para boa parcela de brasileiros e estrangeiros que apreciam a música popular do Brasil.

Um segundo exemplo da forma como a noção de gênero é utilizada para enquadrar e classificar as manifestações musicais advém da discussão de Santos (2018) sobre a cena "global" de metal, em sua etnografia do rock em Angola. Em diálogo com Nilsson (2016) e Kahn-Harris (2007), a autora critica a perspectiva etnocêntrica de parte dos pesquisadores e fãs, na qual ela mesma se filiava até chegar em Angola, que supõe uma homogeneidade das práticas dos fãs de metal, tomando como modelo normativo a cena anglo-saxônica e norte-americana, a partir da qual as outras cenas são avaliadas como cópias bem ou mal feitas. Em contrapartida, a partir de um produtivo diálogo com autores da perspectiva descolonial - tal como Mignolo (2007), Quijano (1989; 1992), Gutierrez (2011) e Comaroff e Comaroff (2016), a autora critica a fetichização do metal europeu e norte-americano como uma representação da normalidade invísivel, propondo-se a entender a cena de rock/metal de Angola em seus próprios termos - tais como a mistura de reggae e metal num mesmo palco de um festival; ou a ausência de camisas de bandas internacionais entre os fãs.

Diversos outros trabalhos produzidos no âmbito brasileiro também têm enriquecido a discussão a partir das especificidades de gêneros locais" ou periféricos". É o caso, por exemplo, das análises de Trotta sobre o forró eletrônico (2014); Tobias Queiroz sobre a cena metal em Mossoró (2015); Soares sobre o brega recifense (2017); Pereira de Sá sobre o funk carioca (2017); Alonso (2015) sobre o sertanejo; Vladi (2015) sobre o arrocha; e Castro \& Lemos (2008) sobre o tecnobrega - dentre muitos outros. Trabalhos que buscam fugir das dicotomias entre centro e periferia e que problematizam as classificações naturalizadas dos gêneros supostamente cosmopolitas 
versus suas expressões locais, o que nos leva à discussão sobre as disputas de valor e construção do gosto.

\section{Valor e gosto como performance}

A discussão em torno de valor e gosto é central ao entendimento das ressonâncias da noção de gênero musical, vez que o gosto é um dos principais marcadores da experiência de fruição dos produtos culturais. Contudo, longe do entendimento do gosto como uma experiência estável e intrínseca ao sujeito ou à obra, nossa abordagem vai percebê-lo, primeiramente, como o resultado de práticas coletivas, baseadas em relações afetivas - seja com outros que compartilham as mesmas preferências, seja com as obras e produtos culturais que nos afetam. Assim, entende-se que as vivências em torno dos gêneros musicais devem ser percebidas como experiências sensíveis-sensoriais que constroem sentidos de pertencimento identitário e também, concomitantemente, de exclusão daqueles que não compartilham os mesmos afetos e valores.

Um segundo aspecto fundamental da discussão, que se desdobra dessa primeira premissa é o de apontar a dimensão performática da noção de gosto. Ou seja: a construção do gosto a partir de um conjunto de práticas, que envolvem os "amantes" (e também os haters) dos produtos culturais, das quais resultam vínculos - que podem ser mais ou menos evanescentes e instáveis - entre "pessoas e coisas". Assim, os gêneros musicais operam como importante mediadores de espaços, lugares, temporalidades, cenas, artefatos midiáticos, apresentações ao vivo e escutas e não como simples intermediações diante da música.

As hierarquias em torno da questão dos gêneros musicais, as disputas simbólicas que envolvem o gosto e a busca dos rastros a fim de identificar quem são os atores humanos e não-humanos que constituem os coletivos musicais, como eles constroem alianças e como os mediadores atuam também ganharam força nos estudos brasileiros, conforme veremos no próximo tópico.

\section{Performance de gosto no ambiente da cultura digital}

Um conjunto bastante expressivo de trabalhos do campo de estudos de som e música no Brasil tem se utilizado da noção de gênero musical para analisar a circulação da música no ambiente da cultura digital

Num primeiro grupo, temos trabalhos que analisaram a mediação das plataformas de streaming, os sistemas de recomendação musical baseados no gosto dos usuários e as práticas de tagging e folksonomia nas plataformas digitais. E que demonstram como os gêneros musicais passam a conviver com outras formas de classificação "subjetivas" 4

4 Por tags como estados psíquicos (tal como uma playlist para um mood melancólico- por exemplo). 
ou que apontam para formas específicas de capital sub-cultural ligado a cenas underground 5 , que contudo não eliminam as negociações, disputas e tensões inerentes aos processos de rotulação musical off-line.

Um segundo conjunto de trabalhos analisa as disputas e performance de gosto dos fandoms e haters nas redes sociais.

Monteiro (2011), em sua pesquisa etnográfica sobre os embates entre fãs e antifãs da banda brasileira Restart nas redes sociais, aponta que uma das acusações dos haters é de que a banda é "colorida demais, rock de menos e basicamente ruim" (MONTEIRO, 2011, p. 4). De acordo com os argumentos desses anti-fãs, "uma banda como Restart não poderia ser classificada como rock, pois elementos sonoros como volume, tom, peso e velocidade caracterizariam o gênero e não aparecem nesses artistas" (AMARAL; MONTEIRO, 2013, p. 456).

Holzbach et al. (2015) e Inocêncio (2017) também abordam os embates entre gêneros musicais, partindo da premissa de que a materialidade do ambiente da cultura digital é central para essas práticas paródicas de apropriação, colagem e disseminação viral, com fins sobretudo de produção de humor. Tratam-se assim de práticas que dessacralizam os gêneros e que "desmontam" a sua performance; e que dependem fortemente do conhecimento e repertório dos fãs em relação ao gênero musical parodiado para atingirem seus objetivos.

Pereira de Sá e Cunha (2014), por sua vez, abordaram os estigmas ligados ao funk nas redes sociais, analisando os comentários de fãs - e sobretudo de haters - em torno de um videoclipe de funk veiculado no Youtube com grande sucesso. Destacam a forma como os haters associam o gênero musical funk a um conjunto de valores negativos, tais como "música ruim, música de favelados, música de analfabetos", dentre outros estigmas.

Esses trabalhos, cuja lista não é exaustiva - para além de revelarem as especificidades e complexidades das disputas dos fandoms no Brasil - demonstram, primeiramente, que os ambientes da cultura digital exercem importante papel em torno das polêmicas e negociações que parecem ser basilares à música hoje. Ambientes que complexificam, de maneiras diversas, as relações entre cenas musicais locais, translocais e virtuais ${ }^{6}$ e onde emergem os processos políticos que orientam as disputas em torno das estratégias de autenticidade, distinção e valor cultural de boa parte da produção musical atual.

Além disso, também demonstram que a noção de gênero musical é central aos embates e que o capital sub-cultural dos usuários das redes sociais - traduzido aqui por conhecimentos das regras sonoras, semióticas e de performance dos gêneros é fundamental para a performance de gosto na cultura digital.

5 Ver a discussão de Amaral (2007) sobre a utilização de taggings pela sub-cultura electro-industrial na plataforma Last.fm, na qual a autora ressalta que os participantes compartilham marcadores de estilos pouco conhecidos pelo público mais amplo - tais como EBM, electro, industrial, gothic rock e synth pop - que funcionam como elementos de identificação e distinção.

6 Para uma crítica das categorias de cenas locais, translocais e virtuais, de Bennet ver Pereira de Sá, 2013. 


\section{Considerações finais}

A retomada dos debates em torno da importância das categorizações musicais advindas das pesquisas sobre gêneros musicais no Brasil demonstra que, se em um primeiro momento os trabalhos apropriavam-se de modelos produzidos nos tradicionais centros universitários de língua inglesa para aplicá-los aos fenômenos musicais locais ou buscavam demonstrar a capacidade dos trabalhos brasileiros de serem aplicados à cultura pop global, em um segundo momento, a preocupação com as espacialidades e as territorialidades acabou por exigir dos próprios pesquisadores um olhar mais atento para a singularidade da produção, consumo, circulação e apropriação de música no Brasil. Este fenômeno, antes de significar a criação de paradigmas restritos à nossa realidade, demonstrou outras possibilidades de abordagem dos gêneros musicais para além dos "cânones" da área, resultando importantes contribuições dos estudos de comunicação no Brasil para as pesquisas sobre gêneros musicais.

Assim, antes de ser apenas um exercício cartográfico, a construção deste artigo buscou demonstrar que a complexidade dos fenômenos de rotulação e catalogação da música necessita de uma abordagem densa e com múltiplas entradas que leve em consideração os papéis que pesquisadores, músicos, fãs e críticos exercem em torno da articulação dos gêneros musicais.

Concomitantemente, cabe reafirmar que os estudos no Brasil apontam para a permanência da noção de gênero musical como uma das balizas dos estudos de música em perspectiva comunicacional. Contudo, em vez de postular a primazia dos elementos sonoros para o entendimento dos gêneros musicais, este conjunto de trabalhos - apesar de sua diversidade de abordagens - sugere que uma análise comunicacional da música pressupõe a articulação de elementos sonoros e não sonoros, entendendo que, antes de funcionar como uma camisa de força, os gêneros musicais acionam conflitos, partilhas e negociações, que por sua vez envolvem processos de mediação dinâmicos.

Assim, acreditamos ser possível sistematizar as contribuições aqui mencionadas agrupadas nos seguintes eixos: 1) articulações em torno de performances, práticas coletivas e divisão de papéis inerentes ao mundo da música; 2) vivências em torno de "comunidades de gosto", agrupando seus participantes em públicos e coletividades em experiências musicais transculturais; 3 ) atravessamento da música pelas formações etárias, étnicas, sociais e de gênero; e 4) configurações comunicacionais implicadas nas redes sócio-técnicas que materializam sistemas de produção, circulação, reprodução, consumo e apropriação da música.

Por fim, parece-nos fundamental incorporar a discussão da perspectiva do Sul Global, que nos chama atenção para o fato de que os sistemas classificatórios envolvem relações de poder. E, como tal, pares como centro e periferia, gêneros globais e locais e (mais ou menos) cosmopolitas, se tratados de maneira dicotômica, reproduzem as relações 
hierárquicas norte-sul e devem ser enfaticamente desnaturalizadas e criticadas. Longe de uma "normalidade invisível" - historicamente definida pelos centros de poder - os gêneros musicais constituem-se a partir de embates sobre "o que devem ser" e como são, na prática, apropriados em contextos culturais específicos e singulares.

Jeder Janotti Jr é professor do Programa de Pós-Graduação em Comunicação da Universidade Federal de Pernambuco e pesquisador do CNPq - Bolsa Produtividade.

jederjr@gmail.com

Simone Pereira de Sá é professora titular do Programa de Pós-Graduação em Comunicação da UFF, e pesquisadora $\mathrm{CNPq}$ - Bolsa Produtividade.

sibonei.sa@gmail.com

\section{Referências}

ALONSO, G. Cowboys do asfalto: música sertaneja e modernização brasileira. Rio de Janeiro, Civilização Brasileira, 2015.

AMARAL, A.; MONTEIRO, C. 'Esse roquero não curte': performance de gosto e fãs de música no Unidos Contra o Rock do Facebook - Trabalho apresentado ao GT de Comunicação e Cibercultura da XX Compós. ANAIS da XX Compós, UFJF, Juiz de Fora, 2012.

AMARAL, A. Categorização dos gêneros musicais na Internet - Para uma etnografia virtual das práticas comunicacionais na plataforma social Last.fm. In: FREIRE FILHO, J.;HERSCHMANN, M. (orgs.). Novos rumos da cultura da mídia: indústrias, produtos e audiências. Rio de Janeiro, Mauad, 2007. p. 227-242. (Volume I)

; AQUINO, M. C. Práticas de folksonomia e social tagging no Last.fm. In: ANAIS do SIMPÓSIO BRASILEIRO DE FATORES HUMANOS EM SISTEMAS COMPUTACIONAIS. Porto Alegre, 2008.

BORN, G. Musica and Materialization of Identities. Journal of Material Culture. Sage, vol.16, n.4, p.376-388, 2011.

CASTRO, O.; LEMOS, R. Tecnobrega: o Pará reinventando o negócio da música. Rio de Janeiro, Ed. Aeroplano, 2008.

COMAROFF, J.; COMAROFF, J.L. Theory From The South: Or, How Euro-America is Evolving Toward Africa. London e New York: Routledge, 2016.

CONTER, M. LO-FI: música pop em baixa definição. Curitiba, Ed. Appris, 2016.

DE MARCHI, L. Como monetizar seu vídeo no Youtube? Análise da produção de valor para conteúdos digitais através da lógcia de sentido derivativo - Trabalho apresentado ao GT de Som e Música. ANAIS da XXVI Compós. Univ. Metodista, São Paulo, 2017. 
ESTIVALET, F. V. "Ah, os caras são paulistas": Pública e as não identificações com o indie rock e o rock gaúcho - Trabalho apresentado ao GP Comunicação, Música e Entretenimento. ANAIS do XL Intercom. Curitiba, 2017.

FABBRI, F. Genre theories and their applications in the historical and analytical study of popular music: a commentary on my publications. Doctoral Thesis, University of Huddersfiled (UK).

. Tipos, categorias, generos musicales. ¿Hace falta una teoria? Conferência de abertura da International Association for the Study of Popular Music (IASPM). Havana, 2006 (mimeo).

FERNANDES, C., TROTTA, F.; HERSCHMANN, M. Não pode tocar aqui!? In: Revista E-COMPÓs. Brasília, vol. 18, n. 2, 2015

FRITH, S. Performing Rites: on the value of popular music. Cambridge/ Massachusetts, Harvard University Press, 1996.

FONSECA, D. D. Entre o "brega" e o rock: a reconfiguração da música de Odair José. Dissertacão de mestrado. Programa de Pós Graduação em Comunicação, Universidade Federal Fluminense, 2015

GUTIÈRREZ, A. G. Desclasificados. Pluralismo lógico y violencia de la clasificación. Barcelona: Anthropos Editorial, 2007.

HENNION, A. Pragmática do Gosto. Desigualdade \& Diversidade - Revista de Ciências Sociais da PUC-Rio. Rio de Janeiro. $\mathrm{n}^{\circ} 8$, jan/jul, 2011, pp.253-277

HERSCHMANN, M. Indústria da música em transição. São Paulo, Estação das Letras e Cores, 2010.

HOLT, F. Genre In Popular Music. Chicago e Londres, University of Chicago Press, 2007.

HOLZBACH, A. et al. Heavy Metal x Funk: disputas de gênero na cultura pop a partir do canal Mamilos Molengas. In: PEREIRA DE SÁ, S.; CARREIRO, R.; FERRARAZ, R. (orgs). Cultura Pop. Salvador, EDUFBA, 2015.

INOCENCIO, L R U MINE, NOVINHA?: Videomemes, cenas musicais e performances de gosto em torno do indie e funk. Projeto de tese de doutorado. Niterói, PPGCOM/UFF, 2017. (mimeo.)

JANOTTI Jr, J. Roots do Sepultura e a Reinvenção da MPB - Música Pesada Brasileira.Trabalho apresentado ao GP Comunicação, Música e Entretenimento do XVII Encontro dos Grupos de Pesquisa em Comunicação, evento componente do $40^{\circ}$ Congresso Brasileiro de Ciências da Comunicação. Anais do Intercom. Faculdades Positivo, Curitiba, 2017.

.̀̀ procura da batida perfeita: a importância do gênero musical para a análise da música popular massiva. Revista Eco-Pós. Rio de Janeiro. UFRJ. Vol. 6, n.2, 2003, p31-46.

KAHN-HARRIS, K. Extreme Metal. Music and Culture on the edge. New York, Berg, 2007.

LATOUR, B. Reassembling the Social. Oxford Univ. Press, 2005.

LÓPEZ CANO, R. Favor de no tocar el género. Géneros, estilo y competencia en la semiótica musical cognitiva actual. En: Martí, J. y Martínez, S. (eds.) Voces e imágenes en la etnomusicología actual: Actas del VII Congreso de la SibE. Madrid: Ministerio de Cultura. pp. 325-337.

MIGNOLO, W. Delinking: the rhetoric of modernity, the logic of coloniality and the grammar of de-coloniality. Cultural Studies, 21:2, 2007, pp.449-514.

.A desobediência epistêmica. A opção descolonial e o significado de identidade em política.

Caderno de Letras da UFF. Dossiê: Literatura, língua e identidade. Niterói, n.34, pp.287-324, 2008.

MONTEIRO, C. Fã-milia \#happyrock_:"recomeço" em cores. ANAIS do I Simpósio em Tecnologias

Digitais e Sociabilidade. Salvador-BA, 2011. Disponível em: <http://migre.me/7dt0V>. 
NEGUS, K.; PICKERING, M. Creativity, Communication and Cultural Value. London: Routledge, 2004 PEREIRA DE SÁ, S. Cultura digital, videoclipes e a consolidação da Rede de Música Brasileira Pop Periférica. ANAIS da XXVI Compós. SP, 2017.

Will Straw: cenas musicais, sensibilidades, afetos e a cidade. In: Jeder Janotti Jr; Itania Maria Mota Gomes. (Org.). Comunicação e Estudos Culturais. Salvador: EDUFBA, 2011, v. , p. 147-162.

Se vc gosta de Madonna também vai gostar de Britney! Ou não? Gêneros, gostos e disputa simbólica nos Sistemas de Recomendação Musical - Brasília, Revista E-Compós, vol. 12. N.2, 2009

. As cenas, as redes e o ciberesepaço: sobre a (in)validade da utilização de cena musical virtual. In: Jeder Janotti Jr; Simone Pereira de Sá (Orgs) - Cenas Musicais. Guararema: Anadarco, 2013

PEREIRA DE SÁ, S.; BITTENCOURT, L.; DOMINGUES, D. Rock RJ: articulações entre cenas musicais e dinâmicas de coletivos culturais do estado do Rio de Janeiro. In: PEREIRA DE SÁ, S. et al (orgs.) Música, Som e Cultura Digital: Perspectivas Comunicacionais Brasileiras.RJ, E-Papers, 2016.

PEREIRA DE SÁ, S.; CUNHA, S. E. Controvérsias do funk no YouTube: o caso do Passinho do Volante. Revista Eco-Pós (Online), v. 17, p. 1-14, 2014.

PEREIRA DE SÁ, S.et al. Cartografias do Urbano na Cultura Musical e Audiovisual: Som, Imagem, Lugares e Territorialidades em perspectiva comparada. Projeto inter-institucional UFF, UFPE e Unisinos. Brasília: Edital PROCAD/CAPES, 2013.

QUEIROZ, T. Cenas musicais do rock no interior do Nordeste: estética, identidade e mercado. Trabalho apresentado ao GP Comunicação, Música e Entretenimento. ANAIS do XXXVIII Congresso da Intercom. Rio de Janeiro: UFRJ, 2015.

QUIJANO, A. Colonialidade y Modernidad-racionalidad. In: BONILLO, H (org). Los Conquistados. Bogotá: Tercer Mundo Ediciones, FLACSO, 1992, pp.437-449.

SANTOS, M. We do rock too: os percursos do gênero musical metal no movimento do rock angolano. Tese de Doutorado. Programa de Pós-Graduação em Comunicação. Universidade Federal Fluminense, 2018.

SOARES, T. 'Ninguém é perfeito e a vida é assim': a música brega em Pernambuco. Recife, PE, Ed. Carlos Gomes de Oliveira Filho, 2017.

STRAW, W. Systems of Articulation, Logics of change: Scenes and Communities in Popular Music. Cultural Studies. Vol 5, n. 3(Oct. 1991) 361-375.

TROTTA, F. No Ceará não tem disso não. Rio de Janeiro: Folio Digital, 2014.

VIEIRA DA SILVA, R. "Fiz um boogie pra você, baby!": tensões representativas a partir do primeiro álbum solo de Mano Brown. Trabalho apresentado ao GP Comunicação, Música e Entretenimento. Anais do XL Intercom. Curitiba: Faculdades Positivo, 2017.

VLADI, N. O sotaque pop da sofrência: as estratégias de comunicação do arrocha para se posicionar como música pop mundial. ANAIS do XXXVIII Congresso da Intercom. Rio de Janeiro: UFRJ, 2015. 